\title{
6. \\ PREGLED POVIJESTI RAZVOJA GRADA BENKOVCA
}

\section{Marin Ćurković}

UDK: 930.85(497.5 Benkovac)

Sažetak: Rad predstavlja povijesni pregled razvoja grada Benkovca, od neolita - mlađeg kamenog doba do 20. stoljeća. Autor donosi kronološki slijed povijesno važnih događanja vezanih uz istaknute spomenike kulture i povijesne ličnosti ovoga područja. Ukazuje na stratešku važnost položaja grada u raznim povijesnim, političkim i gospodarskim okvirima, od razdoblja postojanja rimskih vila rustika koje su se nalazile uz nekadašnju rimsku cestu, do suvremenosti. Brojni kulturno povijesni spomenici na benkovačkom kraju svjedoci su burnih vremena i događanja, a u novije vrijeme i mjesto razvoja kulturnog turizma. Povezivanje kulturne baštine zajedno s tradicijom jedan je od čimbenika ukupnog razvoja ovog kraja.

Ključne riječi: Benkovac, razvoj grada, povijesni pregled, Ravni kotari

enkovac je grad u sjevernoj Dalmaciji, smješten tridesetak kilometara istočno od Zadra. Razvio se na prijelazu iz plodnog područja Ravnih kotara u krševito područje Bukovice. Iako se nalazi na istočnom rubu Ravnokotarske ravnice kao jedino veliko gradsko naselje, smatra se središtem tog područja. Razvoj Benkovca odredio je njegov povoljan prometni položaj na mjestu gdje se križaju ceste koje vode iz Zadra prema Kninu te iz Like prema moru. Taj položaj je još više naglašen u 20. stoljeću izgradnjom željezničke pruge Zadar - Knin (1966. godine) te posebno autoceste Zagreb - Split (2005. godine) koja prolazi čitavim upravnim područjem grada.

Prvi tragovi života na području grada Benkovca datiraju još iz doba neolita - mlađe kameno doba (6000. - 2500. g. pr. Kr.): naselje na području današnjeg dijela Benkovca koje se naziva Barice (usp. Marjanović 2012). To je vrijeme kada započinje intenzivnije bavljenje poljoprivredom te formiranje trajnih naselja. Vrijeme brončanog i željeznog doba, vrijeme Liburna, potvrđeno je nalaskom arheoloških predmeta na prostoru Gradine gdje je danas smješten Kaštel Benković (usp. Batovć 1990:51).

Prodorom Rimljana na ovaj prostor Liburni dolaze pod rimsku vlast. Rimljani osnivaju nova naselja (Jader - Zadar) dok druga liburnska naselja, nastala od vremena kasne bronce, zadržavaju domorodačko stanovništvo koje postepeno preuzima rimsku kulturu, običaje i život - romanizacija (Asseria - Podgrađe, Nedinum - Nadin, Corinium - Karin). U samom Benkovcu pronađeni su nalazi rimske kulture na lokalitetima Ponaiti, Glogovac, 
Veleševo. Radi se o rimskim vilama rustikama koje se nalaze uz rimsku cestu koja je vodila od Jadera do Salone.

Od 4. stoljeća na ove prostore prodire kršćanstvo koje se ogleda u gradnji prvih crkava. Nakon provale Avara i Slavena u 7. stoljeću uništavaju se mnoga velika naselja na ovom prostoru. Dolaze novi narodi, Slaveni, pa tu zamire život kršćanskih zajednica. Tragovi Slavena posvjedočeni su i sačuvani u toponimiji uokolo užeg centra Benkovca (Perušić, Veleševo i Sv. Vid) (usp. Bačić 1989).

Okolnosti su se bitno izmijenile na početku 9. stoljeća, kada je novi car Zapada Karlo Veliki odlučio Bizantu preoteti Jadran. S njegovom vojnom akcijom stiže novo, vojnički organizirano stanovništvo, Hrvati, koji kao vazali franačkog cara preuzimaju upravljanje Dalmacijom i tu se trajno naseljavaju. Kao podanici kršćanskog cara prihvaćaju kršćanstvo i organiziraju svoju prvu državnu zajednicu pod vodstvom kneza. Upravo u prostoru sjeverne Dalmacije ustanovljuju svoja ključna vojna (Knin) i crkvena središta (Nin, Biograd). Benkovački se prostor našao u središtu "svetog" prostora Hrvata, na pola puta između Knina i Nina, odnosno Biograda, na cesti koja se u dokumentima naziva Velika cesta (Via magna), a koja je dijelom paralelna suvremenoj vezi između Benkovca i Knina (usp. Jakšić 2000).

Benkovac je smješten u prostoru gdje su se susretale četiri hrvatske županije. Novljanska (Novigrad) sa sjevera, Sidraška (Biograd) sa zapada, Bribirska s juga i Karinska sa sjeveroistoka. Nije pouzdano utvrđeno kojoj bi od njih položaj današnjeg Benkovca pripadao, najvjerojatnije Karinskoj u koju su bila uključena nedaleka srednjovjekovna sela u današnjoj Kuli Atlagića. Sa stvaranjem čvršće državne organizacije jača proces kristijanizacije te se obnavljaju stari crkveni objekti i izgrađuju novi. Izgrađuju ih osobno hrvatski vladari, njihovi župani ili pak franački misionari koji pomažu učvršćivanju kršćanstva u mladoj hrvatskoj kneževini. Gradi se crkva u Šopotu gdje se spominje Branimir kao knez Hrvata (ulomak s Branimirovim imenom - Branimero dux croatorum) (usp. Jakšić 2000).

$\mathrm{Na}$ širem prostoru Ravnih kotara žive Hrvati podijeljeni u rodovske zajednice (dvanaest plemena) koji se u povijesnim izvorima spominju prvi put 1102. godine kada izabiru za kralja Arpadovića Kolomana. Nakon tog sporazuma Koloman je okrunjen za hrvatskog kralja u Biogradu, a članovi spomenutih hrvatskih rodova postaju njegovi vitezovi i zauzimaju poseban položaj u hrvatskom srednjovjekovnom društvu.

Smješteni su na spomenutoj Velikoj cesti i točno su na pola puta između najznačajnijih udaljenih hrvatskih središta, Knina i Nina, odakle stižu često najugledniji sudionici. Srednjovjekovni život uz tu cestu vrlo je intenzivan o čemu nam svjedoče brojne srednjovjekovne crkve (usp. Jakšić 2000).

Od 1409. godine, kada je Venecija kupila od Ladislava Napuljskog prava na Zadar, Nin, Vranu te Novigrad, našla se u benkovačkom kraju granica između Mletačke Republike i Hrvatske. Granica je tekla linijom Nadin i Biljane Gornje koji su ostali na mletačkoj strani, dok su Korlat i Kličevica bila naselja na hrvatskoj strani. Zato se grade utvrde Korlat, Kličevica i dalje Polača prema mletačkoj granici na prvoj liniji, a ponešto iza njih Benković i Perušić. Te dvije posljednje nose nazive prema hrvatskim velikašima koji su ih gradili i koristili. Uz Kaštel Benković sagrađena je i crkva sv. Ante, danas zaštitnika grada Benkovca.

Izgradnjom utvrde od stare hrvatske plemićke obitelji Benkovića na čelu s Ivanom Benkovićem 1468. godine započinje i povijest samog grada Benkovca (usp. Bačić,1989). 
Godine 1527. Benkovac, koji je pripadao župi Gornjoj Luci, a u crkvenom pogledu ninskoj biskupiji - župa Perušić, zauzimaju Turci te on postaje feud bega Benkovića iz Livna. Iz opisa bosanskog beglerbega Ibrahimpaše iz 1620. godine doznajemo da je taj mali grad bio opasan jednom nenastanjenom kulom s malo kuća u blizini (30 vojnika), što se ponavlja u jednom opisu iz 1624. godine. Sastavljač povijesti zadarske plemićke porodice Begna navodi da je 1650. godine kaštel Benković zapalio Karlo de Begna. Benkovac je u vremenu 1683. - 1699. godine s ostalim mjestima oslobođen od Turaka te je pao pod mletačku vlast (usp. Bačić 2002).

Mlečani su u ratovima protiv Turaka uvelike koristili kršćanske prebjege iz udaljenijih prostora Osmanskog Carstva i naseljavali ih u Dalmaciji, na terene koje su napustili starosjedioci, čakavci, u doba turskih nadiranja i turske vladavine. To je vrijeme velikih migracija u kojem se na taj prostor naseljava novo stanovništvo, uglavnom štokavci. Prema religijskoj pripadnosti dijele se na katolike (Hrvate) i pravoslavce (Srbe). Među jednima i drugima ima puno Vlaha ili, kako ih mletački izvori nazivaju, Morlaka.

Godine 1743. u Benkovcu je osnovana kapelanija, kada je i obnovljena crkva sv. Ante na Kaštelu. Prema katastarskoj mapi iz 1775./6. Benkovac je imao status sela, okruga Zadar te je brojio samo nekoliko stambenih objekata od kojih su neki pripadali poznatoj obitelji Borin (usp. Rimac, 2012).

Nakon mira u Campo Formiju 1797. godine te mira u Požunu 1805. godine Benkovac potpada pod francusku upravu. Pod tom upravom započinje razvoj Benkovca u pravnom i gospodarskom pogledu.

Godine 1806./7. izgrađena je Primorska cesta koja je povezivala Zadar preko Benkovca sa srednjom i južnom Dalmacijom, a 1806. godine ukidanjem Grimanijeva zakona, benkovački seljaci postaju ekonomski slobodni s davanjem porezne desetine (usp. Obad, 1988., 259).

Za vrijeme francuske uprave 1811. godine Benkovac je podignut na razinu seoske općine tzv. sindikata koja je započela s radom 1812. godine. Tako Benkovac, prvi put u svojoj povijesti, postaje upravno središte. 1813. godine općina broji 5200 stanovnika, a načelnik općinskog vijeća je Anđelo Borin (usp. Obad 1988: 260). Godine 1813. Benkovac potpada pod austrijsku upravu pod kojom se zadržao do 1918. godine, odnosno do njenog raspada nakon Prvog svjetskog rata.

Radi potreba kontrole i nadzora vlasništva zemlje te plaćanja poreza 1827 . godine napravljen je tad moderan katastar. Općina Benkovac je 1827 . godine zauzimala $8,5 \mathrm{~km}^{2}$, dok je sam Benkovac imao 192 stanovnika. Zahvaljujući cestovnoj komunikaciji Benkovac trgovački jača te se u 1827. godini u Benkovcu nalazi prva poštanska stanica s mjenjačnicom te bažana, karantena za životinje i odmorište za trgovačke karavane (pojava benkovačkog sajma koji traje do danas). Nažalost, krajem 1827. godine ukinuta je općina Benkovac, ali taj je period trajao jako kratko (usp. Obad 1988:261).

Četrdesete godine Benkovcu donose značajan razvoj. Godine 1840. osnovana je župa Benkovac, župnik - don Ivan Glasnović, a 1843. te 1847. godine Benkovac dobiva prvog kirurga i doktora za stanovnike Benkovca. 1. siječnja 1847. godine Benkovac ponovno dobiva rang općine te postaje i pretura (kotar) koji je obuhvaćao dvanaest sela. Prvi pretor bio je Juraj Katnić, dok je za prvog načelnika postavljen Ante Bašić, a pomoćni su mu Ivan Kornereto i Stjepan Borin. Pojavom općine i preture povećava se broj stanovnika, otvaraju se novi obrti, radionice, trgovine (obitelj Novakovići, Jurkovići, Katurići...). Pojačava 
se razmjena dobara. Počinje se uobličavati nova glava ulica (današnja šetnica) te se život postepeno razvija uokolo ulice. U preturi Benkovac većina stanovništva je katoličke vjere. Prva osnovna škola osnovana je 1860. godine, a vodio ju je svećenik don Blaž Blasul (usp. Bačić 1989).

Formiranjem Benkovca kao političkog kotara 1868. godine grad se razvija kao urbano središte koji svoj razvoj zasniva na poljoprivredi i trgovini (pekara, krčme, trgovina duhana i soli). Godine 1863. započelo se s gradnjom katoličke crkve Male Gospe koje je dovršena 1864. godine. Nadbiskup Petar Dujam Maupas crkvu je posvetio rođenju Blažene Djevice Marije 8. rujna 1864. godine (usp. Stagličić 1985:229). Crkva Male Gospe bila je smještena u centru Benkovca, unutar pošumljenog vrta koji je $s$ istočne strane bio omeđen župnom kućom. Orijentacija crkve bila je sjeveroistok-jugozapad, s pročeljem koje gleda prema glavnoj ulici. Kameni zvonik crkve bio je visok $20 \mathrm{~m}$. Sa sjeverozapadne strane zvonika uklesan je natpis cara Franje Josipa koji je pomogao dovršenje zvonika, a crkvu posjetio prilikom svog posjeta Benkovcu 1875. godine. U prvoj polovini 1992. godine crkva je miniranjem srušena do temelja od strane pobunjenih Srba i jugoslavenske vojske.

$\mathrm{Na}$ drugom kraju grada prema Bukoviću sagrađena je današnja crkva sv. Jovana, kako je zabilježeno i na natpisu nad bočnim ulazom u crkvu, 1885. godine pri carevanju austro-ugarskog cara i kralja Franje Josipa I. Na njenom mjestu bila je stara katolička crkva posvećena sv. Ivanu, a još prije nje prema arhivskim zabilježeno je na istom mjestu postojanje srednjovjekovne crkve sv. Vida na lokalitetu Vuković (usp. Bačić 1989).

U školskoj godini 1875./76. u Benkovcu školu pohađa 34 učenika, a učitelj je Andrija Pelicarić. Nadzornik osnovnih škola u benkovačkom školskom kotaru bio je Josip Škarpa, učitelj Vježbaonice u Zadru (usp. Zaninović 1988:270).

Godine 1870. za općinskog načelnika izabran je Nikola Dapar. Bio je član Narodne stranke gdje je zastupao grad Benkovac u Dalmatinskom saboru. Od 1891. godine. bio je zastupnik u Carevinskom vijeću u Beču. Nije se slagao s oportunističkom politikom svoje stranke te je 1894. godine postao član Stranke prava za Dalmaciju. Zalagao se za sjedinjenje Dalmacije s tadašnjom banskom Hrvatskom.

Godine 1883. predsjednik općinskog vijeća bio je Petar Novaković (stari). Za vrijeme njegova upravljanja Benkovac se jako razvija. Grade se prve umjetne mlinice na parni pogon (1912.). Razvija se urbani građanski sloj. Prate se trendovi zapada što je vidljivo u arhitekturi (secesija), stilu odijevanja, školovanju, trgovini, a 1910. otvorena je Prva hrvatska čitaonica. U isto je vrijeme kupljen prvi automobil u gradu. Javljaju se prve amaterske fotografije i tisak razglednice (usp. Arhiv Obitelji Novaković, DAZd)

Od 1914. do 1918. funkciju općinskog načelnika obnašao je sin Petra Novakovića, Mihovil, koji je za vrijeme Prvog svjetskog rata 1914. sudjelovao u radu Crvenog križa u Benkovcu. Od 1918. do 1921. Benkovac se nalazi pod talijanskom upravom te cvjeta ilegalna trgovina i šverc. Kada je na ruševinama Austro-Ugarske Monarhije poslije Prvog svjetskog rata stvorena Država Srba, Hrvata i Slovenaca, a nešto kasnije i Kraljevina Jugoslavija, napetosti na relaciji Srbi - Hrvati postajale su sve izrazitije. U istom vremenskom okviru Mihovil Novaković se aktivira u stranačkom radu HSS te reprezentira stavove hrvatskog puka. Godine 1927. Mihovil Novaković (Mićo) postaje predsjednik HSS-a za benkovački kraj te dovodi Stjepana Radića u Benkovac. Već 1931. postaje općinskim predsjednikom, ali za kratko jer je nakon donošenja Oktroiranog ustava doslovno izbačen kroz prozor (usp. Plenča 1988:319). 
Što se tiče kulturnog života u Benkovcu je 6. lipnja 1924. utemeljeno društvo Sokol. Društvo je u samom početku okupljalo 90 članova, a za starostu je izabran sudac Marko Marić. U kolovozu iste godine održan je sokolski slet u Benkovcu u kojem su sudjelovala sokolska društva iz Šibenika, Drniša, Kistanja i Novigrada. Benkovački je sokol prvi svoj javni nastup imao godinu dana po osnutku. Početkom tridesetih godina 20. stoljeća osnovane su sokolske čete u Pristegu, Polači, Škabrnji, Galovcu, Zemuniku, Smokoviću, Murvici, Privlaci i drugim mjestima. Društvo je brojilo oko 900 članova. Od 1927. društvo je imalo i vlastiti glazbeni sastav. U Benkovcu je 1934. godine započela izgradnja Sokolskog doma, tzv. "Sokolane". Poslije Drugog svjetskog rata zgrada je završena i tada dobiva drugu funkciju. Postaje Dom Jugoslavenske narodne armije u kome je bilo smješteno kino i kazalište. Danas je taj prostor prenamijenjen u Dom kulture. Godine 1933. umire Mihovil te ga u nastavku obrtničkog i trgovačkog razvoja Benkovca nasljeđuje sin Petar (Pjer). Bio je istaknuti HSS-ovac čiju predsjedničku funkciju obavlja do 1944. godine. Petar Novaković, osnivač Nogometnog kluba Velebit, donio je 1909. godine prvu nogometnu loptu kupljenu u Trstu u trgovini Emanuela Fidlera (usp. Marić 2005).

Za vrijeme Pjera snažno se razvija Matica hrvatska u Benkovcu čiji je aktivni član i on sam. To je vrijeme kada Benkovac svoj razvoj zasniva tradicionalno na poljoprivredi, trgovini i obrtu.

Za vrijeme Drugog svjetskog rata Benkovac su prvotno okupirali Talijani, da bi nakon 1943. potpao pod vlast Nijemaca. Nakon Drugog svjetskog rata Benkovac se razvija kao središte Ravnih kotara i Bukovice. Primarna grana je poljoprivreda i vinogradarstvo. Godine 1956.157. sagrađena je Vinarija Benkovac koja je aktivna do danas. Razvija se privreda, obrada metala, prerada kamena, graditeljstvo. Grade se novi stambeni blokovi i zgrade. Godine 1950. otvoren je Vatrogasni dom i osnovana Javna vatrogasna postrojba Benkovac, a 1966. godine izgrađena je željeznička pruga Zadar - Knin koja prolazi kroz Benkovac. Narodno sveučilište Benkovac osniva se 1959. godine i postaje nositeljem kulturnog razvoja Benkovca (kino, kazalište, muzej, knjižnica, auto-škola, kulturno-umjetničko društvo). Godine 1981. otvoren je hotel Asseria sa 106 ležaja. To su novi početci obavljanja turistič́ke djelatnosti u Benkovcu.

Povijest 20. stoljeća na benkovačkom kraju završava osamostaljenjem Hrvatske 1990. godine i Domovinskim ratom. Nakon rata 1995. godine stanovništvo benkovačkog kraja vraća se na stara ognjišta i kreće u obnovu svojih crkava i domova. Prije Domovinskog rata, u sastav tadašnje općine Benkovac ulazile su i današnje općine Lišane Ostrovičke, Polača i Stankovci. Reformom lokalne uprave 1996. godine, Benkovac je dobio status grada i priključeno mu je područje ukinutih općina Lisičić i Smilčić. Grad Benkovac danas se sastoji od 41 naselja, a prema Popisu stanovništva iz 2011. godine, administrativno područje grada Benkovca imalo je 11026 stanovnika (usp. Državni zavod za statistiku, 2011).

Zahvaljujući bogatom kulturno-povijesnom nasljeđu i kulturnim spomenicima u Benkovcu je osamdesetih godina prošlog stoljeća započela s radom mala arheološka zbirka koja je kasnije prerasla u Zavičajni muzej Benkovac. Nakon Domovinskog rata muzej je dugo bio u devastiranom stanju da bi 2008. godine ponovno započeo s radom. Upravo muzej postao je jedan od značajnih pokretača revitalizacije i prezentacije bogatog kulturnog nasljeđa ne samo Benkovca nego cijelog benkovačkog kraja. Prostor Kaštela Benković, u kome je smješten Zavičajni muzej Benkovac, postao je ishodišta točka za upoznavanje benkovačkog kraja. Nakon dobivenih podataka o povijesti posjetitelj samostalnim istraživanjem kreće u upoznavanje i obilazak brojnih lokaliteta. 
U muzeju se organiziraju mnoga predavanja i radionice u suradnji s brojnim institucijama iz cijele regije, ali i šire s ciljem edukacije lokalnog stanovništva u očuvanju tradicije.

Zajedno s Turističkom zajednicom grada Benkovca krenulo se u novije vrijeme s aktivnom prezentacijom te spajanjem kulture i turizma. Prije nekoliko godina započelo se $s$ programom "Benkovačko kulturno ljeto" koje obuhvaća preko dvadesetak manifestacija i događanja, kroz koje se prezentiraju kulturna, gastronomska i prirodna ponuda benkovačkog kraja i okolice. Manifestacije tipa "Festival prisnaca", "Vinfest", "Bukara", smotre klapa i "Etnofestival" te druge, primjer su aktivnog spajanja stanovništva i struke, s ciljem očuvanja i prezentacije kulture i tradicije. Upravo ovakva događanja osmišljena su s ciljem prezentacije brojnih mogućnosti koje pruža bavljenje poljoprivrednom (vinogradarstvo, maslinarstvo), pogotovo ekološkom koja zajedno s gastronomijom i iznimnom kulturnom baštinom i tradicijom na benkovačkom području pruža iznimne mogućnosti za razvoj turizma i življenje od njega. Rječju - održivi razvoj.

U novije vrijeme zahvaljujući suradnji s obitelji Desnica i prof. Roksandićem u kulturnu ponudu uključuje se i sklop Kule Stojana Jankovića, izniman kulturni spomenik koji se nalazi na području Grada Benkovca te koji zahvaljujući svojim aktivnostima privlači brojne posjetitelje. Bogate zbirke koje posjeduje Kula vrijedne su zajedničke suradnje na prezentaciji ovog iznimnog kulturnog spomenika.

Stoga je potrebno povezati benkovački Muzej zajedno s Kulom kako bi se dobila izvrsna mogućnost izrade turističkih tura, kako autobusnih tako i biciklističkih koje prolaze nedaleko te bi se i na taj način povezala Kula i njezine znamenitosti.

Zaključno rezimirajući, prostor Grada Benkovca, njegova povijest, kulturno-povijesna baština, prirodne ljepote te gastronomska ponuda idealan su spoj za razvoj kulturnog turizma, koji obogaćen ekološko proizvedenom hranom i tradicijskim vrijednostima vrijednih ljudi Ravnih kotara i Bukovice pruža idealnu mogućnost za održivi razvoj stanovništva na ovom području.

\section{$\cos$}

\section{Literatura}

BAčrć, fra Stanko. 1989. Perušić, župa Marijina Uznesenja u Zadarskoj nadbiskupiji. Split: Knjižnica zbornika "Kačić".

BAČić, fra Stanko. 2002. "U XV. stoljeću postojala su dva Benkovića (Benkovca)”. U Hrvatska u doba kneza Branimira. Zagreb - Zadar - Benkovac: Hrvatski institut za povijest - Matica hrvatska Zadar - Povjereništvo Matice hrvatske Benkovac i Grad Benkovac, 197-206.

Batović, Šime. 2004. Benkovački kraj u prapovijesti. Zadar: Matica hrvatska Zadar.

JaKšić, Nikola. 2000. Benkovac i okolica u srednjem vijeku. Split: Muzej hrvatskih arheoloških apomenika.

MARIĆ, Drago. 2005. 80 godina HNK Velebit. Zadar: Zadiz.

Овар, Stijepo. 1988. "Gospodarska i društvena struktura Benkovca u prvoj polovici devetnaestog stoljeća”. Benkovački kraj kroz vjekove, Zbornik 2. Benkovac - Zadar: Općinska konferencija Socijalističkog saveza radnog naroda SR Hrvatske, Benkovac - Filozofski fakultet Zadar, 256-267.

PlenČA, Dušan. 1988. "Benkovački kotar između dva svjetska rata". Benkovački kraj kroz vjekove, Zbornik 2. Benkovac - Zadar: Općinska konferencija Socijalističkog saveza radnog naroda SR Hrvatske, Benkovac - Filozofski fakultet Zadar, 301-333. 
Rimac, Marko. 2012. Zadarsko okružje na mletačkom katastru iz 1709. godine. Zagreb -Zadar: Hrvatski državni arhiv - Državni arhiv Zadar.

Stagličić, Marija. 1985. "Neostilska arhitektura u zadarskoj regiji., Prilozi povijesti umjetnosti u Dalmaciji, br. 25. Split: Književni krug Split - Konzervatorski odjel u Splitu, 229-257.

Marijanović, Brunislav. 2012. "Barice-naselje danilske kulture u Benkovcu). Archaeologia adriatica, vol. 6, Zadar: Sveučilište u Zadru, Odjel za arheologiju, 1-30.

ZANinović, Mate. 1988. "Benkovački kotar između dva svjetska rata”. Benkovački kraj kroz vjekove, Zbornik 2. Benkovac - Zadar: Općinska konferencija Socijalističkog saveza radnog naroda SR Hrvatske, Benkovac - Filozofski fakultet Zadar, 269-289.

Arhiv Obitelji Novaković, DAZd [0431] OBITELJ NOVAKOVIĆ-Benkovac, 1826. - 1956., Državni arhiv Zadar. 